\title{
SCRN and the Industrial Integration of Suxichang Metropolitan Economic Circle
}

\author{
Ming Chen \\ School of Business Soochow University Suzhou, China \\ cm192@163.com
}

Keywords: Metropolitan Economic Circle; Supply Chain; Logistics; 3PL

\begin{abstract}
The Network of Supply Chain Resource (SCRN) is the effective carrier to promote the integration of Suxichang metropolitan economic circle. A mathematical model of the specialization and division theory of the new classical microeconomics has been made to analyze the benefit of SCRN in the industry integration of metropolitan economic circle. At present, the integration of Suxichang metropolitan economic circle is far from being realized. Therefore, we should give full play to the advantages of information flow and network platform, especially,construct the SCRN platform, to achieve the communication, interaction, feedback and integration of the information of supply chain resource. Thus, we can realize the integrated utilization of the various kinds of supply chain resource of metropolitan economic circle. The Suxichang metropolitan economic circle can take the lead in building a SCRN platform with practical value, so as to promote the industrial integration in this area.
\end{abstract}

\section{Introduction}

Suzhou, Wuxi and Changzhou three cities have formed a prominent metropolitan economic circle (The Suxichang Metropolitan Economic Circle) in the Yangtze River Delta Economic Circle by their unique location advantages and economic advantages. Whether it is to cooperate with Shanghai, or to strengthen economic cooperation with neighboring provinces, The status of Suxichang Metropolitan Economic Circle is very prominent. It should play the role of the vanguard of economic development in the Yangtze River Delta region. However, due to the long administrative division, which makes the industrial structure of the three cities similar, the resources have not been effectively integrated, and the competition between the three cities is much greater than their cooperative relationship. We propose that, taking the integration of logistics resources as the starting point, constructing the Supply Chain Resource Network (SCRN) platform, and promoting the integration of logistics of Suzhou, Wuxi and Changzhou by virtual supply chain integration is a feasible way to realize the industrial integration and the coordinated development of Suxichang Metropolitan Economic Circle.

In recent years, the theories and methods of supply chain management and supply chain management have been studied deeply. Bhardwaj B.(2016)[1] has put forward a sustainable strategy driven supply chain resource management model (GSCM); Basaez M, Aranda D. \& Djundubaev R. et al. (2015) [2] have put forward a customer oriented supply chain management model; From the perspective of dynamic capability, Vargas J.\& Mantilla C. (2015) [3] have studies the new enterprise management model of sustainable supply chain management (SSCM); By using the method of large data analysis, Prasad S, Zakaria R. \& Altay N. (2016) [4] have put forward the construction method of supply chain network. By applying the above theory and the theory of specialization and division of labor in the new classical microeconomics, we will study the method and model of industrial integration in Suxichang Metropolitan Economic Circle through the construction of Supply Chain Resource Network.

\section{The Industrial Integration of Suxichang Metropolitan Economic Circle is far from Being Achieved}

Industrial integration is one of the main characteristics of economic integration of metropolitan economic circle. The so-called economic integration refers to the division of labor and cooperation 
between the central cities in the metropolitan area are closely related to each other, integration of all the factor markets, (including capital, labor, technology and other factors of production in the metropolitan area of the city and between urban and rural areas), integration of industry integration, infrastructure integration, resource development and environment protection and city integration [5]. But the reality is that, for a long time, due to the administrative division and the symbolic, have made the industrial structure between Suzhou Wuxi and Changzhou highly similar, the competitive relationship between each other is much greater than the cooperative relationship, the mobility of factors has not been fully developed, the liquidity factor has yet to give full play to the far, far from achieving industrial integration, the industrial integration of Suxichang Metropolitan Economic Circle is far from being achieved.

According to the latest third national economic census data, At the end of 2013, in the categories of industry, The computer communications and other electronic equipment manufacturing, the digital textile industry, the electrical machinery and equipment manufacturing industry practitioners are the top three of the proportion of employees in Suzhou City, accounted for $25.7 \%$, 9\% and 7.7\%[6]; The computer, communications and other electronic equipment manufacturing, the general equipment manufacturing, the electrical machinery and equipment manufacturing industry ranks three in the top digit of the proportion of employees in Wuxi city, respectively, accounting for $12.5 \%, 11.1 \%$ and $9.0 \%$ [7]; The electric machinery and equipment manufacturing, the general equipment manufacturing, computer, the communications and other electronic equipment manufacturing industry, are the top three of the proportion of employees in Changzhou City, accounting for 12.6\%, 12.1\% and 9.4\%[8], As shown in Figure 1, figure 2 and figure 3. Other industrial structure characteristics also show that the industrial structure of Suzhou, Wuxi and Changzhou are highly similar, coincident and competitive.

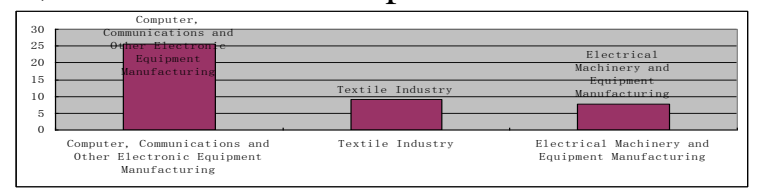

Figure 1. The proportion of employees of the top three industries in Suzhou city

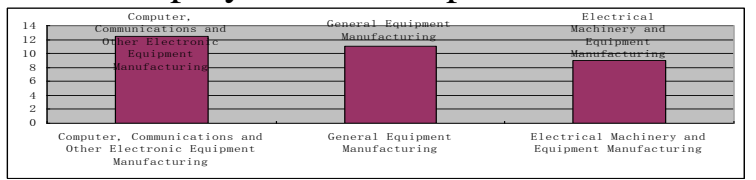

Figure 2. The proportion of employees of the top three industries in Wuxi city

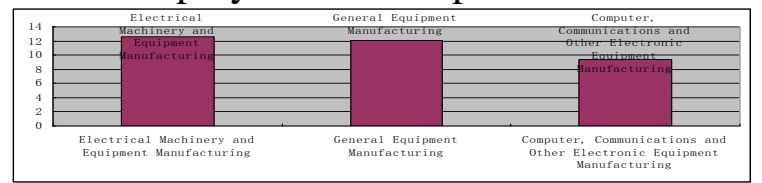

Figure 3. The proportion of employees of the top three industries in Changzhou city

At present, the Yangtze River Delta is facing a new round of development situation, The time for Suxichang metropolitan economic circle to give full play to their respective advantages and realize the coordinated development of industrial integration is ripe. In order to realize the economic integration of Suxichang metropolitan economic circle, we must avoid the excessive similarity of industrial structure and realize the dislocation development. To achieve dislocation development, it is necessary to integrate the resources of the three cities, change the industrial overlap into industrial complementarities. To this end, it is imperative to break the administrative barriers, realize the market integration, industrial docking, and harmonious development of Suxichang metropolitan economic circle. Therefore, we should take the integration of logistics in Suxichang metropolitan economic circle as the starting point, give full play to the advantages of information flow and network platform, and construct SCRN network platform. First of all, we should realize the virtual integration of supply chain resources of Suxichang metropolitan economic circle, and then realize the integration and docking of the industries of Suxichang metropolitan economic circle. 


\section{Realize the Industrial Integration of Suxichang Metropolitan Economic Circle by the Virtual Supply Chain Integration}

Because of the role and status of modern logistics industry in the overall economy is very prominent, the integration of logistics has become the starting point of the integration of Suxichang metropolitan economic circle. Logistics is the circulation system of modern economy; it is responsible for the protection of raw materials, semi-finished products, finished products of the transport, storage and associated with the flow of funds, information flow. So, logistics is the driving force for the integration of metropolitan market and industrial docking. There is a widespread phenomenon of industrial overlapping in Suxichang metropolitan economic circle currently. It has caused the high cost, excessive competition, multiple transportation, multiple transfer and other economic phenomena, it forms a huge waste of resources, but also highlights the importance of the integration of logistics resources in Suxichang metropolitan economic circle.

Since entering the new century, China's logistics industry is in a period of great development. According to the new accounting of China Logistics Information Center, from January 2016 to November, China's total social logistics is for 208.8 trillion yuan, calculated at comparable prices, with an increase of $6.2 \%$. Among them, the total industrial logistics is for 194.5 trillion yuan, calculated at comparable prices, with an increase of 6\%; From January 2016 to November, China's total social logistics costs 9.6 trillion yuan, with an increase of $3.6 \%$, among them, transportation costs 5.0 trillion yuan, with an increase of $4.5 \%$; storage costs 3.2 trillion yuan, with an increase of $1.5 \%$; management costs 1.3 trillion yuan, with an increase of $5.7 \%$; Over the same period (January 2016 to November), China's logistics industry total revenue is of 7.0 trillion yuan, with an increase of 5.3\%[9]. Data show that the scale of China's logistics market continues to expand, the operating efficiency has been improving, its support and promotion to economic development is becoming more obvious.

The Yangtze River Delta (especially the Suxichang metropolitan economic circle) is one of the most active areas in China. A large number of foreign-funded enterprises in this region have created a large logistics demand. Taking Suzhou as an example, in the first half of 2015, the city's total social logistics in Suzhou amounted to 2403.394 billion yuan, with an increase of $1.6 \%$, Total social logistics costs 103.168 billion yuan, with an increase of $10.6 \%$. Total logistics costs accounted for $14.6 \%$ of GDP [10], compared with the same period in 2014, increased by one percentage point, indicating that the logistics industry in Suzhou showed a sustained development trend.

But ill-adapted to the situation, the development of 3PL in Suxichang metropolitan economic circle is still faltering. At present, there are many 3PL enterprises in Suxichang metropolitan economic circle. But most of them are based on the traditional transportation or warehousing enterprises. They are small-scale, decentralized operation, low organized, lacking of independent logistics brand, lacking of effective supply of logistics, especially fail to meet the high-end demand of logistics. Many large business customers are not satisfied with the service of the 3PL and tend to self-support logistics. The 3PL enterprises have to cut prices for a small number of large enterprise customers, resulting in the lack of development potential, resource allocation, overlapping business, market disorder of logistics markets. In addition, local protection, regional blockade and industry monopoly still exists in Suxichang metropolitan economic circle to a certain extent, the construction of the legal system of logistics is lagging behind, resulting in the costs of 3PL enterprises is difficult to fall, many of them are facing difficulties.

Taking Suzhou as an example, the number of all kinds of logistics enterprises in Suzhou is more, but on the whole is still in the "small, low, scattered, weak" state. There is a contrast between the number of logistics enterprises and the added value of logistics, reflecting the overall efficiency of the logistics industry in Suzhou is not high. The situation in Wuxi and Changzhou is similar to that in Suzhou.

The only way to solve the problem is to integrate logistics resources. Carry on the supporting, joint, complementary and integration to the large number of scattered, small-scale 3PL resources in Suxichang metropolitan economic circle. Judging from the current situation, the integration approach is mainly two: First, is to encourage capital integration. Therefore, should encourage the 
transport, warehousing, distribution, freight forwarding, multimodal transport enterprise to asset restructuring through mergers, equity participation, joint venture and other forms, foster a number of professional and competitive 3PL enterprises. Second, is to make the strength, promising traditional transportation, warehousing enterprises bigger and stronger, develop them to become the leading enterprises in Suxichang metropolitan economic circle. Thus, they can promote the integration of logistics resources in Suxichang metropolitan economic circle, absorb the logistics resources of the local and neighboring cities, extend their logistics services from the local to the surrounding cities, and then lead to the emergence of new logistics services. So, they can really complete the transformation from traditional transportation, warehousing enterprises to modern 3PL enterprises.

However, the success cases are not common. More logistics enterprises are still lack of coordination. The reason is the division of logistics resources. To break the administrative division, from the perspective of local government, they should accelerate the integration of logistics resources. From the view of Suzhou, Wuxi and Changzhou three cities, there are many detailed assumptions of local logistics development. However, under the current system, the planning of the three municipal government can only play a role in their respective administrative areas, and not compatible with the requirements of the construction of the logistics network system in some aspects. Suzhou, Wuxi and Changzhou three cities all have put forward the idea of building regional logistics center. However, due to the limitations of administrative areas, their respective planning can only be divided into their own administrative divisions, but not beyond the boundaries. This situation is contrary to the requirements of modern logistics.

The requirement of modern logistics is "integration", but as a prefecture level city, Suzhou, Wuxi and Changzhou can only integrate the resources of each city. But in fact, it is more important to focus on integrating the resources of all the three cities. Suzhou, Wuxi and Changzhou have formed a relatively integrated urban economic circle in the Yangtze River delta. They should cooperation and complementary together. However, as mentioned above, from the perspective of industrial structure of Suzhou, Wuxi and Changzhou, their industrial structure is highly similar and intense competition. One important reason is that the resources are not effectively integrated in these three cities.

Therefore, it is worth emphasizing that the logistics resources of Suzhou, Wuxi and Changzhou three cities must be integrated firstly, so as to promote the integration of other resources. But obviously, the respective plan of each city is difficult to achieve this goal. In terms of physical resources, due to the limitation of administrative divisions, block segmentation will inevitably occur, it is difficult to achieve coordinate and integration. In this sense, the construction of SCRN platform, realize the virtual logistics and supply chain integration, is not only the need of logistics enterprises, but also is the need for the Suxichang metropolitan economic circle to achieve the integration of resources, complementary and coordinated development of the industry.

\section{Constructing the SCRN Platform to Realize the Virtual Integration of Supply Chain Resources in Suxichang Metropolitan Economic Circle}

In recent years, the municipal governments of Suzhou, Wuxi and Changzhou all have put forward the countermeasures of developing modern logistics industry. The Suzhou municipal government has put forward "Opinions on Further Accelerating the Development of Producer Services" in November 6, 2014[11]. About the modern logistics industry, it has proposed to speed up the development of 3PL and 4PL, promote the integration of the logistics industry and the manufacturing industry, continue to improve the multi-level logistics system in Suzhou, so as to improve the service level of bonded logistics center, vigorously develop modern business logistics, promote supply chain management to provide lean service for manufacturers, improve the supply chain financial model system, and strengthen the construction of comprehensive logistics and professional logistics public information platform and cargo stowage center. Wuxi and Changzhou municipal government also have proposed similar plans in the same period. 
We believes that, in order to achieve the above-mentioned plans proposed by Suzhou, Wuxi and Changzhou municipal government, we must realize the coordinated and integrated development of logistics industry of Suxichang metropolitan economic circle. The construction of SCRN network platform and the realization of virtual integration of logistics resources in the area of Suzhou Wuxi and Changzhou is an effective way to realize the coordinated development of logistics industry of Suxichang metropolitan economic circle.

SCRN is a network system which has achieved the communication, interaction, feedback and integration of logistics information, so as to monitor the material flow, capital flow, so as to realize the integration and utilization of all kinds of logistics resources. Its function is centered on the orders of end customer, coordinate with material flow, business flow, information flow and capital flow, so as to achieve the rapid reaction to customer orders and customer demands. The goal of SCRN is to integrate the whole supply chain, namely: connect end-users, distributors, manufacturers, suppliers, and so on, build a supply chain network with multiple links, and form a rapid, accurate and efficient integration of virtual supply chain network, which is characterized by timely triggering, monitoring and feedback of information flow.

The features of SCRN include: according to the needs of the members of the supply chain network, realizing the combination of design, manufacturing, sales, storage, distribution, handling, packaging, distribution processing and other logistics function, establishing the interaction between supply chain, providing real-time logistics information query, browsing, and matching, automatic completing the logistics transaction, tracking goods in transit, implementing the logistics path planning, intelligent logistics scheduling and so on.

The operating procedures of SCRN include: issuance and interaction of logistics information, matching of logistics transaction, order management, channel management, transportation management, and warehouse management and so on, then, achieving the goal of providing logistics solutions and logistics value-added services for production enterprises, sales enterprises and 3PL enterprises.

The function and benefit of SCRN platform in Suxichang metropolitan economic circle can be analyzed by the theory of specialization and division of the New Classical Microeconomics. For SCRN, which specializes in the virtual integration of supply chain, its product is the "industrial integration" itself. As a product, "industrial integration" is needed by every market participant, so it has a higher preference parameter, and it can be considered that "industrial integration" is also a highly specialized product. It can be proved that the "industrial integration" itself as a trade product (that is, there is purchasing and selling of "industrial integration" services, as well as the existence of SCRN system platform) can get a higher average income level.

For convenience, we can assume that there are only two kinds of products: X, Y. Among them, $\mathrm{X}$ is a general product, $\mathrm{Y}$ is the product of "industrial integration". In Yang Xiaokai's New Classical Theory[12], the utility of the combination $(\mathrm{X} / \mathrm{Y})$ and $(\mathrm{Y} / \mathrm{X})$ can be expressed as:

$$
\begin{aligned}
& \ln u(x / y)=\alpha\left(2 \ln x+\ln r-\ln M_{x y}\right)+\gamma \ln z+\alpha \ln K \\
& \ln u(y / x)=\alpha\left(2 \ln x+\ln r+\ln M_{x y}\right)+\gamma \ln z+\alpha \ln K
\end{aligned}
$$

Among(1),(2): $K=[2 \alpha /(3 \alpha+\gamma)]^{\alpha} / 2, \quad z=[\gamma /(3 \alpha+\gamma)]^{\alpha}, \quad r=[\alpha /(3 \alpha+\gamma)]^{\alpha}$,

The condition of utility equality is:

$$
E=\ln u(y / x)-\ln u(x / y)=2 \alpha \ln m_{x y}=0
$$

Let $\mathrm{u}^{*}$ be the real income, $\mathrm{M}^{*} \mathrm{xy}$ is the relative number of the enterprise which select different combinations in this corner equilibrium. From the formula (3), it can be:

$d M_{x y}^{*} /\left.d \alpha\right|_{\alpha=\gamma}=-(\partial E / \partial \alpha) /\left.\left(\partial E / \partial M_{x y}\right)\right|_{\alpha=\gamma}=0$

Among (4), $\partial E /\left.\partial \alpha\right|_{\alpha=\gamma}=2 \ln M_{x y}=0$, If: $\alpha=\gamma$, then $M_{x y}=1$. At the same time, it can be:

$\partial \ln u * /\left.\partial \alpha\right|_{\alpha=\gamma}>0$

Therefore, it can be: 
$d \ln u^{*} /\left.\partial \alpha\right|_{\alpha=\gamma}=\left.\partial \ln u^{* / \partial \alpha}\right|_{\alpha=\gamma}+\left.\left(\partial \ln u^{*} / \partial M_{x y}\right)\left(d M_{x y}^{*} / d \alpha\right)\right|_{\alpha=\gamma}>0$

That is to say, the higher average income level is obtained by the corner equilibrium which uses the larger preference parameter product as trade product.

Suppose that $\alpha=\beta=\gamma, a=b=h, \alpha=\beta=\gamma, a=b=h$, then:

$x=[2 a /(3 a+c)]^{a} / 2, z=[c /(3 a+c)]^{a}, M_{x y}=[2 a /(3 a+c)]^{a}$

Then, formula (1) and formula (2) are established, the condition of utility equality is formula (3). $\mathrm{Use}^{[2 a /(3 a+c)]^{a} / 2,[c /(3 a+c)]^{a},[2 a /(3 a+c)]^{a}}$ to replace $\mathrm{x}, \mathrm{z}$, Mxy in formula (1),(2), it can be:

$$
\begin{aligned}
& \partial \ln u * /\left.\partial a\right|_{a=c}>0 \\
& d M_{x y}^{*} /\left.d a\right|_{a=c}=-(\partial E / \partial a) /\left.\left(\partial E / \partial M_{x y}\right)\right|_{a=c}=0
\end{aligned}
$$

Among (8), $\partial E /\left.\partial a\right|_{a=c}=0, E$ is given by formula (3). Thus we obtained:

$d \ln u * /\left.\partial \alpha\right|_{a=c}=\partial \ln u * /\left.\partial \alpha\right|_{a=c}+\left.\left(\partial \ln u * / \partial M_{x y}\right)\left(d M_{x y}^{*} / d \alpha\right)\right|_{a=c}>0$

That is to say, the higher average income level is obtained by the corner equilibrium which uses the higher professional rewarding product as trade product.

Because of the above two conclusions, and in the condition that "industrial integration" is the product whose specialization and preferences are all higher, the existence of an independent "Industrial integrator" has a higher average income level. The platform specializing in "industrial integration" is SCRN. The existence of SCRN has created a higher average income level. That is, SCRN can change the bilateral relations of industry into integration of industry, as shown in figure 4:

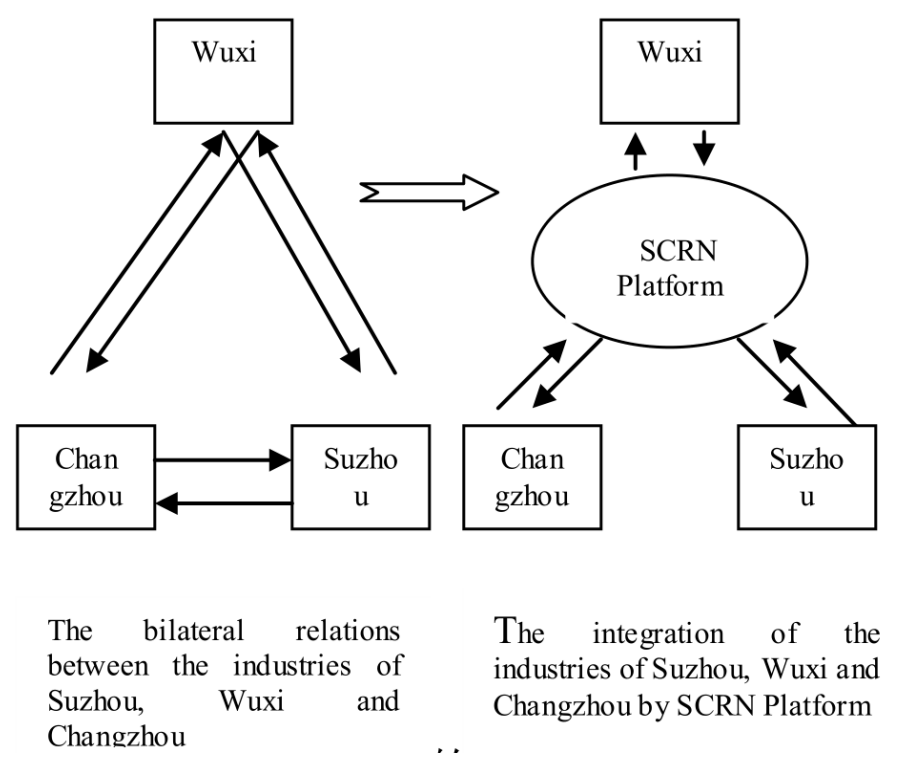

Figure 4. The bilateral relations and integration of the industries of Suzhou, Wuxi and Changzhou

In general, because of the Internet technology has improved the efficiency of transaction. It has changed the product of "industrial integration" from autarky into division. Due to the division of labor, the professional platform of SCRN has been formed. Since 1990s, the rapid development of information technology and the popularity of information infrastructure, creating a higher transaction efficiency conditions, thus, has given the possibility of the emergence of SCRN platform. Also, as mentioned earlier, the rapid development of logistics of Suxichang metropolitan economic circle has great demand for SCRN platform. Therefore, the construction of SCRN platform is not only full of necessity, but also full of feasibility. It must be put on the schedule as soon as possible. 
The economic and information technology level of Suxichang metropolitan economic circle is at the forefront of China. Suxichang metropolitan economic circle should give full play to the advantages of network platform, take the lead in building a SCRN platform with practical value. From the point of view of implementation, SCRN should put the software construction in the first place, and make unified planning for construction, operation and management. The construction of SCRN platform must consider the following factors:

Construction of powerful, strong radiation, safe and efficient wireless network system

The logistics demand of Suxichang metropolitan economic circle is huge. Therefore, its SCRN platform network system must be complete, powerful, strong radiation, safe and efficient. Not only has the high efficiency of the central processing system, but also has wide range tentacles deep inside each member enterprise, forming a large-scale parallel processing of virtual supply chain network platform. To this end, the whole system should use client-server-database three layer structure based on the wireless network, and implement multi machine fault-tolerant mechanism and data backup mechanism. At the same time, due to the information of SCRN platform involves the business secret, it is necessary to establish a perfect firewall mechanism and access control mechanism.

A. Import cloud data and big data technology, Construct intelligent decision support system, support supply chain optimization

Supply chain optimization decision is an important function of SCRN. The software system of SCRN platform must introduce business intelligence function, implement data warehouse technology, cloud data technology, data mining technology and big data technology, and construct an intelligent decision support system to support the SCRN supply chain optimization and meet the needs of users at all levels of supply chain network.

B. Achieve the coordination of virtual supply chain network and physical supply chain network

SCRN platform is characterized by the full display of the value of network information flow, but not without any physical facilities. Virtual logistics network based on information flow must cooperate with physical logistics network. Logistics center should plan its own streaming facilities and node facilities in a certain geographical area, and achieve efficient, agile and low cost logistics process among these nodes.

According to the current characteristics that the 3PL enterprises in Suxichang metropolitan economic circle are not perfect, the SCRN can set up its own logistics distribution center if necessary. This distribution center will cooperate with production enterprises, sales enterprises, logistics companies and end customers, and form an quick response logistics network in Suxichang metropolitan economic circle.

\section{Conclusions}

SCRN is an effective carrier to promote the industrial integration of Suxichang metropolitan economic circle. The theory of specialization and division has revealed its role and benefits in the industrial integration of metropolitan economic circle. At present, the industrial integration of Suxichang metropolitan economic circle is far from being realized. Therefore, we should give full play to the advantages of information flow and network platform, construct supply chain resource network (SCRN) platform, and achieve the communication, interaction and feedback of supply chain information, so as to achieve the integration and utilization of various resources in Suxichang metropolitan economic circle.

The construction of SCRN platform with practical value in Suxichang metropolitan economic circle will achieve the integration of material flow, capital flow, workflow, and service flow based on the information flow of supply chain system in this area, so as to promote the integration of all kinds of supply chain resources in this area, and then promote the realization of industrial integration of Suxichang metropolitan economic circle. 


\section{Acknowledgment}

Thanks to the Philosophy and Social Sciences Foundation of Jiangsu, China, No.(04EYB022).

\section{References}

[1] Bhardwaj B R. Sustainable supply chain management through enterprise resource planning (ERP): a model of sustainable computing[J]. International Journal of Management Science \& Business Administration, 2015, 1:166 - 171.

[2] Basaez M O, Aranda D A, Djundubaev R, et al. The Role of CRM - SRM Bolt - ons in Enterprise Resource Planning System: Toward a Customer - Oriented Supply Chain[J]. Strategic Change, 2015, 23(5-6):389-400.

[3] Vargas J R C, Mantilla C E M. Sustainable supply chain management capabilities: a review from the resource-based view, the dynamic capabilities and stakeholder theories[J]. 2015, 1(4):323.

[4] Prasad S, Zakaria R, Altay N. Big data in humanitarian supply chain networks: a resource dependence perspective[J]. Annals of Operations Research, 2016:1-31.

[5] Dai bin. Analysis of Urban Agglomeration and Its Related Concepts [J]. Finance and Economics Science.2004. (6):101-103. (In Chinese)

[6] The Office of the Third National Economic Census Leading Group in Suzhou, the Suzhou Municipal Bureau of Statistics, National Bureau of Investigation Team in Suzhou. The Main Data Bulletin of Suzhou of the Third National Economic Census [R]. Bulletin of Suzhou Municipal People's Government.2015-2-11. (In Chinese)

[7] The Office of the Third National Economic Census Leading Group in Wuxi, the Wuxi Municipal Bureau of Statistics, National Bureau of Investigation Team in Wuxi. The Main Data Bulletin of Wuxi of the Third National Economic Census [R]. Bulletin of Wuxi Municipal People's Government. 2015-3-24. (In Chinese)

[8] The Office of the Third National Economic Census Leading Group in Changzhou, the Changzhou Municipal Bureau of Statistics, National Bureau of Investigation Team in Changzhou. The Main Data Bulletin of Changzhou of the Third National Economic Census [R]. Bulletin of Changzhou Municipal People's Government. 2015-2-12. (In Chinese)

[9] China Federation of Logistics and Purchasing.2016 1-11 Logistics Operation Briefing in January to November,2016[R]. http://www.chinawuliu. com.cn[R].2016-12-23. (In Chinese)

[10]Cbiw. Suzhou social logistics statistics in the first half of 2015[EB/OL]. http://www.askci.com/news/chanye. 2015-9-21

[11] Suzhou Municipal People's government. Opinions on Further Accelerating the Development of Producer Services [R]. Bulletin of Suzhou Municipal People's Government.2014-11-6. (In Chinese)

[12] Yang Xiaokai, Huang Youguang. Specialization and economic organization [M].2000. pp.149. (In Chinese) 